LICENÇA CC BY:

Artigo distribuído sob os termos

Creative Commons, permite uso e distribuição irrestrita em qualquer meio desde que o autor credite a fonte original.

\title{
JOGOS, AFETOS E POTÊNCIAS: NOVIDADES APARECIDAS NO TEATRO DO OPRIMIDO NA SAÚDE MENTAL
}

\author{
GAMES, AFFECTIONS AND POTENTIALS: NEW APPARITIONS IN THE \\ THEATER OF THE OPPRESSED IN MENTAL HEALTH \\ JUEGOS, AFECTOS Y POTENCIAS: NOVEDADES APARECIDAS EN EL \\ TEATRO DEL OPRIMIDO EN LA SALUD MENTAL
}

Deise Juliana Francisco ${ }^{1}$

Claudete do Amaral Lins ${ }^{1}$

${ }^{1}$ Centro de Educação, Universidade Federal de Alagoas, Maceió, AL, Brasil.

Resumo: Neste artigo, apresentamos a potência que os jogos, os diálogos e a atuação cênica produziram nos corpos de pessoas com sofrimento psíquico durante oficinas de teatro do oprimido em um Centro de Atenção Psicossocial (CAPS) da cidade de Maceió. A pesquisa teve a duração de sete meses, na qual participaram 30 usuários. $O$ estudo articulou o encontro entre o teatro do oprimido, a terapia ocupacional, a saúde mental e a educação com o objetivo de conhecer como o teatro do oprimido operou na produção de subjetividade e na singularização de pessoas com sofrimento psíquico. A fundamentação da pesquisa se deu por meio da teoria dos afetos de Espinosa. Os resultados apontam para a potência dos jogos, a subjetividade e as singularidades vivenciadas, a construção da história e os efeitos produzidos nos participantes e no público.

Palavras chave: Jogos; saúde mental; teatro do oprimido; Espinosa; educação.

Abstract: This article presents the power produced by games, dialogues and scenic performance in the bodies of people with psychological distress, during theater workshops for the oppressed at a Psychosocial Care Center (CAPS) in the city of Maceió. A survey was conducted over a period of seven months, with the participation of thirty users. The study articulated the encounter between the theater of the oppressed, occupational therapy, mental health and education, in order to understand how the Theater of the Oppressed operated in the production of subjectivity and in the singularization of people with psychological distress. The research was based on Espinosa's theory of affects. The results point to the power of the games, the subjectivity and singularities experienced, the construction of the story and the effects produced on the participants and the public.

Keywords: Games; mental health; theater of the oppressed; Espinosa; education.

Resumen: En este artículo presentamos el poder que los juegos, los diálogos y la representación escénica produjeron en los cuerpos de las personas con sufrimiento psíquico durante los talleres de teatro de los oprimidos en un Centro de Atención Psicosocial - CAPS en la ciudad de Maceió. La encuesta duró siete meses, en los que 
participaron 30 usuarios. El estudio articuló el encuentro entre el teatro de los oprimidos, la terapia ocupacional, la salud mental y la educación para comprender cómo funcionaba el Teatro de los oprimidos en la producción de subjetividad y en la singularización de las personas con sufrimiento psíquico. La investigación se basó en la teoría de los afectos de Espinosa. Los resultados apuntan al poder de los juegos, la subjetividad y las singularidades experimentadas, la construcción de la historia y los efectos producidos en los participantes y el público.

Palabras clave: Juegos; salud mental; teatro de los oprimidos; Espinosa; educación.

\section{Introdução}

Este artigo tem como objetivo apresentar a potência que os jogos do Teatro do Oprimido, assim como a atuação cênica, produziram nos corpos das pessoas com sofrimento psíquico durante uma pesquisa de mestrado em educação. A dissertação de mestrado articulou o encontro entre teatro do oprimido, terapia ocupacional, educação e saúde mental com o objetivo de conhecer como o Teatro do Oprimido operou na produção de subjetividade e na singularização de pessoas com sofrimento psíquico durante as oficinas de Teatro do Oprimido.

"A Novidade Aparecida" foi o nome sugestivo dado à história real de gravidez na adolescência, manicomialidade, machismo, falta de acolhimento familiar, internação produzida pelos oficineiros usuários de um Centro de Atenção Psicossocial de Maceió. A peça trata também de uma história de 21 anos de uma mulher, em meio à vida, às crises, ao cuidado com o filho.

Foram realizados jogos, assim como diálogos e reflexões sobre a vida, outras possibilidades de vivência com o corpo e novas maneiras de afetar e ser afetado pelo outro, bem como apresentações na comunidade, em teatros e universidades.

Neste percurso, fomos em busca de uma teoria para nos ajudar a entender, a conhecer melhor o que se passa conosco quando adentramos no terreno da produção da subjetividade. Para nossa surpresa, encontramos num filósofo do século XVII elementos para se pensar a nossa prática terapêutica, na medida em que esse mesmo filósofo desenvolveu toda uma rica teoria dos afetos, repleta de insights brilhantes e originais, que podem ajudar bastante na nossa compreensão dos processos de subjetivação numa perspectiva clínico-social.

A seguir apresentaremos uma noção básica da metodologia do teatro do oprimido, assim como introduziremos a teoria dos afetos de Espinosa antes de apresentarmos os resultados da pesquisa, isto é, os efeitos, os afetos e as potências produzidas pelo Teatro do Oprimido.

\section{Teatro do Oprimido}

Augusto Boal, teatrólogo brasileiro, criou ao longo de mais de 40 anos de trabalho a metodologia do Teatro do Oprimido. Algumas técnicas foram desenvolvidas no Brasil e outras em países da América Latina e Europa a partir da década de 1970, após seu exílio. 
A Árvore do Teatro do Oprimido (Figura 5) é uma forma de sintetizar a metodologia, representando todos os elementos que compõem o método, o universo de possibilidades de transformações, seu caráter político e solidário voltado para a culminância de ações concretas com comunidades e grupos vulneráveis com os quais atua, isto é, os oprimidos (BOAL, 2008; SANTOS, 2016).

A solidariedade e a ética são o solo da experiência; os jogos, sua estrutura e base para a criação e as diversas técnicas são as possibilidades de transformação. "A Ética e a Estética, seiva que alimenta a Grande Árvore do TO, viajam pelas veias axiais da Palavra, Imagem e do Som, principais raízes, e transitam pelos jogos - Metáfora da realidade" (BOAL, 2008, p.73). A Filosofia, a História, a Participação e a Política compõem o meio externo e a necessidade de articulação para alcançar a transformação desejada, o pássaro representa o ativismo para a organização e a multiplicação.

Figura 1 - Cenário da peça e seu autor

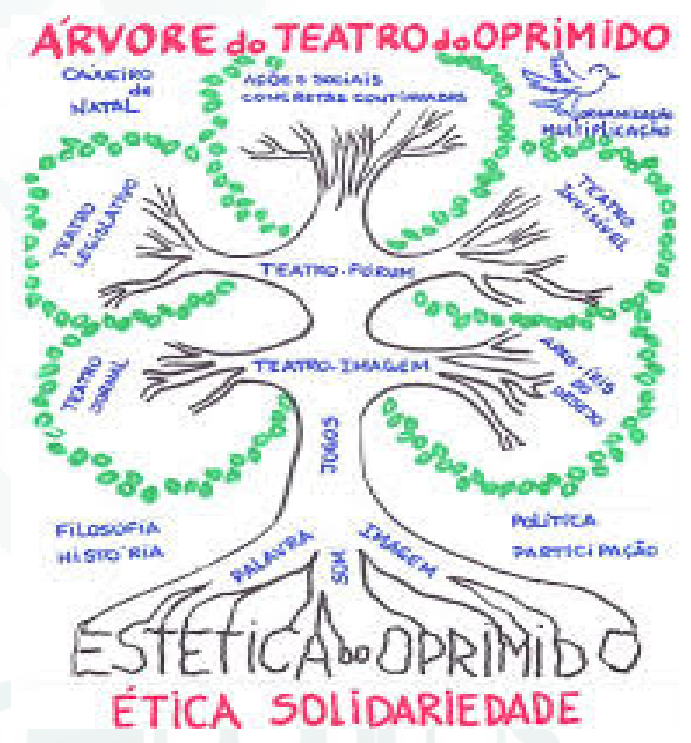

Os jogos e exercícios compõem o Arsenal do Teatro do Oprimido, são mais de 400 jogos e exercícios construídos ao longo de seu trabalho e são a base para praticar o método; o trabalho começa pelos jogos que prepara o ator (BOAL, 2015).

Boal chama de exercício o trabalho que é feito com o movimento, com os músculos, trabalho motor, respiratório, espaço e todas as outras relações que o corpo estabelece no ambiente. Eles servem para conhecer o corpo e refletir sua capacidade física. Os jogos tratam da expressividade: "Os Jogos são um diálogo, eles exigem um interlocutor, eles são 'extroversão'" (BOAL, 2015, p. 97).

Boal (2015) parte do princípio de que o ser humano é uma unidade, não havendo separação entre o físico e o psíquico, os sentidos também estão todos interligados. O corpo então, para dar conta de tantas mensagens e exigências, necessita se adaptar, o que pode levar a uma atrofia e uma hipertrofia. Boal propõe esses jogos porque percebeu que o corpo necessita de um rearranjo para ser capaz de emitir e receber mensagens de uma maneira mais 
eficaz, e o que ele propõe com os jogos é o caminho da desespecialização. Para realizar essa desespecialização, categorizou os jogos de acordo com o tipo de sensorialidade (sentido) a ser potencializada. São cinco as categorias: $1^{\text {a }}$ Sentir tudo o que se toca; $2^{a}$ Escutar tudo que se ouve; $3^{a}$ Ativando os vários sentidos; $4^{a}$ Ver tudo que se olha; e $5^{a}$ A memória dos sentidos. Os jogos trabalham muitas coisas ao mesmo tempo, no entanto os jogos de cada categoria estão mais voltados para um foco específico:

Na primeira categoria, procuramos diminuir a distância entre sentir e tocar; na segunda, entre escutar e ouvir; na terceira tentamos desenvolver os vários sentidos ao mesmo tempo; na quarta categoria, tentamos ver tudo aquilo que olhamos. Finalmente, os sentidos têm também uma memória, e nós vamos trabalhar para despertá-la: é a quinta categoria. (BOAL, 2015, p. 99).

O Teatro do Oprimido possui exercícios e técnicas que potencializam encontros, possibilitam diálogos, expressão e o entendimento sobre as opressões e o sofrimento vivenciados pelos participantes. O Teatro-Fórum é potente para ampliar o entendimento e ensaiar mudanças na sociedade, novas formas de ver e de agir, uma vez que vai além do teatro tradicional, impulsionando a plateia a sair do papel de espectadora e subir ao palco para propor as alternativas que a protagonista oprimida não pode exercitar. Vale ressaltar que no teatro do oprimido são contadas histórias reais de opressão, que guardam sua singularidade, mas também refletem a realidade coletiva.

O Teatro do Oprimido, ao trabalhar a partir da opressão vivenciada, desvela as linhas e as forças vivenciadas na dialética oprimido - opressor, a impossibilidade de enfrentamento dos conflitos marginalizados que estão presentes nas condições de saúde, educação, na falta de oportunidades de trabalho e de moradia digna.

A metodologia do teatro do oprimido revelou os jogos como preparo e aquecimento para o corpo, possibilitou os fluxos, as repetições e os ritmos vivenciados no processo de construção da peça e toda a emoção e repercussão sentida nos ensaios no CAPS e nas apresentações.

Fomos afetados pelos jogos e técnicas do Teatro do Oprimido. Conhecer o corpo, sentir, perceber o que se passa com o meu corpo, com o corpo do outro, e nesse encontro o que se produz? Possibilidades, intensidades, certezas, incertezas, alegrias, tristeza, constrangimento, potência... e como reajo? Ao final das oficinas e, às vezes, durante a realização dos jogos, fazíamos um diálogo sobre as impressões, os sentimentos despertados, o que foi vivido corporalmente e as dificuldades apresentadas por cada um.

\section{A teoria dos afetos em Espinosa: o que pode um corpo?}

Tomamos a filosofia prática de Espinosa descrita por Deleuze e outros comentadores, assim como a ética espinosana para fundamentar os encontros, as afecções e os afetos produzidos pelos 
corpos e mentes dos participantes em um percurso com o Teatro do Oprimido. A Filosofia prática de Espinosa, sua concepção sobre Deus e a Natureza, a relação mente e corpo, o conatus, a teoria dos afetos e os três gêneros de conhecimento, estes foram os conceitos que deram base para produzir a narratividade do que aconteceu no encontro dos nossos corpos nas oficinas de Teatro do Oprimido. Como fomos afetados e nos afetamos mutuamente?

Pessoas que estão em sofrimento estão marcadas por conflitos, impossibilidades, dores, tristezas, mas também fluxos instáveis de alegria e por falta de oportunidades diversas capazes de ordenar tais fluxos de afetos. Essa marca advém da construção da relação entre o normal e o patológico construída em nossa sociedade ao longo da história. Canguilhem nos mostra como a relação entre o que é normativo é prejudicial à nossa vida. Segundo o autor, "normar é impor uma exigência a uma existência" (CANGUILHEM, 2009, p.109).

Espinosa (2016) descreve vários afetos paixões nocivos à vida, flutuações que aumentam e diminuem nossa potência de agir quando não conseguimos entender nossos afetos de alegria, tristeza e desejo. Nossa felicidade depende com isso da forma como interagimos no mundo, oportunidades e contextos a que estamos submetidos, a forma como nos deixamos afetar pelas coisas. Se somos passivos, isto é, se apenas sofremos os efeitos desses encontros, imaginando saber o que se passa conosco apenas pelas marcas e pelos resíduos deste encontro; ou se adotamos uma postura mais ativa, buscando aprender a refrear os afetos nocivos e selecionando aqueles que nos sãos úteis e aumentam nossa potência. Ser ativo ou passivo, no entanto, não depende apenas de nós, uma vez que vivemos em coletividade e estamos submetidos a fluxos e forças sociais variados. -

Alegria, desejo e tristeza são afetos primários inerentes à vida. Segundo Espinosa (2016), é através do desejo e da alegria que alcançamos a liberdade, no entanto, o homem foi moldado para coibir seus afetos, se tornando passivo frente às adversidades da vida, desenvolvendo sentimentos como o medo e a esperança. Na sociedade, é valorizado o ser forte, nossas dificuldades são sempre malvistas.

Para Espinosa (2016), nas primeiras definições, axiomas e proposições da Ética I, Deus ou Natureza é causa de si, é infinita e é eterna, não precisa de nada para existir, é de sua essência a existência: "Por causa de si entendo aquilo cuja essência envolve a existência; ou seja, aquilo cuja natureza não pode ser concebida senão como existente" [Definição 1 da Ética 1]. (SPINOZA, 2016, p. 13).

Historicamente foi se construindo uma ideia que se tornou hegemônica, a supervalorização do primado da razão (mente) sobre o corpo. Acreditamos assim que nossa vontade pode nos libertar das nossas paixões, julgando ter um livre arbítrio e sermos livres quando possuímos o poder da vontade, regulando nossas paixões e escolhas, isto é, que nossa mente é capaz de agir sobre nosso corpo regulando nossos apetites e anseios (CHAUÍ, 2016; SPINOZA, 2016).

Espinosa rompe com todas essas crenças, com essas concepções e tradições filosóficas, que fazem parte da maneira de pensar da grande maioria dos seres humanos.

Julgamos saber o que se passa conosco através da nossa razão. No entanto, nos alerta Espinosa: "As ideias das afecções do corpo humano, à medida que estão referidas apenas à mente humana, não são claras e distintas, mas confusas" [Proposição 28 da Ética 2] (SPINOZA, 2016, p. 35). 
Para Espinosa, não há uma supremacia da mente sobre o corpo; segundo Deleuze (2002), ele nos provoca a responder, afirmar, mostrar o que pode um corpo? (DELEUZE, 2002). Deleuze (2002) afirma que Espinosa toma o corpo como modelo, que é para nos mostrar que o corpo vai além do que sabemos a seu respeito. Espinosa (2016) nega a supremacia da mente sobre o corpo, a ideia de que é através das ideias que conhecemos o corpo, e de que precisamos da mente para fazer agir o corpo. Segundo Deleuze (2002),

É, pois, por um único e mesmo movimento que chegaremos, se for possível, a captar a potência do corpo para além das condições dadas do nosso conhecimento, e a captar a força do espírito, para além das condições dadas da nossa consciência. (DELEUZE, 2002, p. 24).

Para Espinosa (2016), a relação mente e corpo se dá concomitantemente através de nossas afecções, isto é, do encontro entre os corpos. Estas afecções ocorrem em graus de variação e flutuação constante que se operam aumentando e diminuindo nossa potência de existir.

Mas o que é um corpo para Espinosa? Segundo Deleuze (2002), podemos defini-lo de duas formas: como uma infinidade de partículas e suas relações de repouso e movimento ou, por outro lado, por sua capacidade de afetar e ser afetado por outros corpos.

A forma como Espinosa (2016) nos demonstra a relação entre corpo e mente, e entre conatus e desejo, nos impulsiona a buscar novas abordagens. Abordagens tais como o Teatro do Oprimido, as quais favoreçam a potência dos indivíduos para a ação, isto é, para a construção dos afetos - ações.

Segundo Espinosa (2016), nosso conhecimento sobre as coisas, a maneira como atuamos sobre e somos afetados pelas coisas, pode nos tornar ativos ou passivos, nos colocando assim no caminho da liberdade ou da servidão. E esta condição de ser ativo ou passivo é central para entender a teoria dos afetos em Espinosa. Deleuze, influenciado pela filosofia prática de Espinosa, nos mostra como o corpo, o encontro de corpos de diversas naturezas, produz paixões e ações.

Não sabemos nada de um corpo enquanto não sabemos o que ele pode, isto é, quais são seus afectos, como eles podem ou não compor-se com outros afectos, com os afectos de um outro corpo, seja para destruí-lo ou ser destruído por ele, seja para trocar com esse corpo ações e paixões, seja para compor com ele um corpo mais potente. (DELEUZE; GUATTARI, 2012, p. 45).

O corpo humano é afetado por outros corpos, de diferentes maneiras, e afeta outros corpos de diferentes maneiras. Somos um sistema em constante transformação. No corolário I da Proposição 16 da Ética 2, Espinosa esclarece que a "mente humana percebe, juntamente com a natureza de seu corpo, a natureza de muitos outros corpos" (SPINOZA, 2016, p. 67). Nossa percepção, nossa mente, assim como nosso corpo, estará sempre em busca da conservação e da reposição de suas necessidades, de forma concomitante.

Somos afetados de muitas maneiras e nossa mente é capaz de percebê-las concomitantemente. Se um corpo sofre muitas modificações, a mente irá produzir muitas ideias. O encontro entre os corpos é expresso em nossa mente sob a forma de afecções e afetos. Tais afecções geram imagens, resíduos que ficam na nossa mente do que foi experimentado pelo encontro dos corpos, pelos nossos sentidos, imagens olfativas, visuais, gustativas, táteis, sonoras. 
Se o corpo humano é afetado de uma maneira que envolve a natureza de algum corpo exterior, a mente humana considerará esse corpo exterior como existente em ato ou como algo que lhe está presente, até que o corpo seja afetado de um afeto que exclua a existência ou a presença desse corpo. [Proposição 17 da Ética 2]. (SPINOZA, 2016, p. 67).

No entanto, nesses encontros essas imagens criadas na mente não são explicitadas, são apenas imagens que não são capazes de fazer com que o corpo volte a existir. É dessa forma que passamos a imaginar, presos que ficamos aos resíduos deixados no nosso corpo e na nossa mente (FERREIRA, 2009; SPINOZA, 2016). Espinosa (2016) nos alerta para a condição de servidão que os homens se submetem quando permanecem limitados a apenas perceber o que acontece quando seu corpo se encontra com outro corpo.

O conatus é o nosso esforço para perseverar na existência (SPINOZA, 2016), força interior que impulsiona o nosso viver. Deleuze (2002) esclarece que o conatus não é uma passagem à existência, mas sim o perseverar na existência e sua duração é indefinida. É o nosso poder de ser afetado e afetar constantemente, quanto mais as afecções produzidas em nós e por nós se tornarem conscientes, os afetos assim passam a se chamar desejo.

E como o homem busca a felicidade? Qual a importância de discernimos o que se passa conosco, uma vez que somos moldados para negar o que sentimos? Mesmo que não sejamos marcados pela negação dos nossos sentimentos, estamos sempre em busca de sermos corajosos, esperançosos, responsáveis, fortes, entre outras maneiras de ser que nem sempre nos sãos úteis.

Passamos ao longo da vida sem conhecer verdadeiramente aquilo que nos afeta, sem conhecer a natureza e as relações que se estabelecem em nossos encontros com outros corpos e mentes. Desprezamos nossos sentimentos, nutrimos sentimentos ambivalentes, brigamos com coisas que nos incomodam, como se nada tivessem a ver conosco, mas, na verdade, muitas das vezes, não conhecemos as razões por que algo nos incomoda tanto.

O homem vive mais na imaginação e por isso em vez de agir, em vez de caminhar para a liberdade, vive na servidão, preso a preconceitos, julgamentos e opiniões (SPINOZA, 2016).

Segundo Espinosa (2016), toda ação é interessada, é marcada por algum interesse; se admitimos esse fato, podemos distinguir o que é bom e útil para nós, e o que é mau. Quando agimos para nos conservar, isto é, perseveramos na nossa existência, na nossa potência de existir, somos virtuosos. "Agir absolutamente por virtude nada mais é, em nós, do que agir, viver, conservar o seu ser [...], sob a condução da razão, e isso de acordo com o princípio de buscar o que é útil para si próprio" [Proposição 24 da Ética 4] (SPINOZA, 2016, p. 172). Neste sentido, é próprio do homem, da sua natureza, buscar o que é bom, o que compõe com o nosso corpo e com a nossa mente.

Mas e o que são afecções e afetos para Espinosa?

Por afecções entendemos os encontros produzidos pelos corpos e pelas mentes ao longo da nossa existência. Espinosa (2016) distingue duas afecções, as ações (atividade) e as paixões (passividade). As afecções experimentadas por nós ao longo da vida podem ser mais passivas do que ativas se desconhecemos as variações e as intensidades vividas, se desprezarmos uma parte significativa daquilo que nos marca. Assim, desprezaremos a oportunidade de construir nossos afetos - ações. 
Desconhecemos as possibilidades de conhecer melhor, entender o que passa nos nossos encontros, nas afecções produzidas em nós pela enorme variedade de encontros e nos afetos produzidos em nossas mentes (DELEUZE, 2002; SPINOZA, 2016).

Somos ativos quando temos ideias adequadas, quando podemos entender de forma clara aquilo que foi produzido em nós, isto é, "[...] agimos quando, em nós ou fora de nós, sucede algo de que somos a causa adequada..." [Definição 2 da Ética 3] (SPINOZA, 2016, p. 98). Somos passivos quando não conseguimos distinguir ou conhecer de forma clara aquilo que se passa conosco, quando conhecemos de forma parcial e inadequada as coisas (SPINOZA, 2016). Criamos imagens dos encontros que temos com pessoas e coisas. É assim que Espinosa nos afirma que a mente é a ideia do corpo.

A teoria dos afetos em Espinosa, traduzida nesta capacidade do ser humano de passar da paixão à ação, isto é, da passividade (imagem, imaginação) para a atividade (conhecimento das coisas), pode ser encarada como uma orientação primordial para nós terapeutas. É através do conhecimento dos seus afetos, isto é, quando conseguimos não mais produzir ideias inadequadas que nos levam à tristeza, ao desequilíbrio, ao desvalor, ao medo para utilizar algumas das mais comuns às pessoas com sofrimento psíquico, é aí que o ser humano consegue entender o que sente verdadeiramente e passa a construir os afetos-ações. A ação terapêutica que se orienta para estimular o entendimento e a responsabilidade e o comprometimento e/ou a implicação da pessoa e da família em seu processo de tratamento faz toda a diferença, pois passa a lidar com a existência - sofrimento e não com uma categoria nosológica que prediz ou que liga um diagnóstico a um prognóstico.

O conhecimento, para Espinosa, se forma a partir de três gêneros de conhecimento: a opinião ou imaginação, a razão e a ciência intuitiva

É através do segundo e terceiro gêneros do conhecimento descritos por Espinosa que alcançaremos a liberdade, seremos produtores de nós mesmos, seremos a causa adequada dos nossos afetos e conseguiremos agir mais, experimentar mais, essa é a medida de sermos capazes de conhecer mais a nossa própria essência.

\section{Metodologia}

Trata-se de uma pesquisa qualitativa, do tipo pesquisa-intervenção que foi realizada articulando uma pesquisa de mestrado e um projeto de extensão. As oficinas de Teatro do Oprimido foram realizadas em um Centro de Atenção Psicossocial da cidade de Maceió no período de janeiro a agosto de 2017.

O Projeto de Extensão Universitária aprovado pelo Edital (omitido para fins de avaliação do artigo) viabilizou a pesquisa realizando 31 oficinas de Teatro do Oprimido durante o período de 7 meses. Participaram da experiência bolsistas das áreas de teatro, dança, pedagogia e psicologia, sendo que as oficinas tiveram a condução de um dos bolsistas, estudante de teatro (hoje já graduado) que tem formação em Teatro do Oprimido pelo Centro de Teatro do Oprimido - CTO - Rio de Janeiro. 
A pesquisa foi iniciada após a aprovação do projeto de pesquisa pelo Comitê de Ética em Pesquisa - CEP - UFAL, em concordância com a Resolução 466/12 e 510/16 e após a aplicação do Termo de Consentimento Livre e Esclarecido - TCLE com os participantes.

Participaram das oficinas um total de 30 participantes, 16 dos participantes foram coprodutores de todo o processo da pesquisa.

O registro de cada oficina foi realizado através de gravação em vídeos, fotografias e áudios dos diálogos realizados antes e/ou depois das oficinas, além do registro em diário de campo. Os nomes dos participantes da pesquisa foram divulgados por solicitação dos mesmos, sendo solicitada autorização do Comitê de Ética em Pesquisa para fazê-lo.

Ao longo do processo foram vivenciados pelos participantes: uma média de 20 jogos do arsenal do Teatro do Oprimido (sendo que alguns foram repetidos em várias oficinas), diálogos no início e no fim de cada oficina, 3 meses de construção da peça, ensaios dentro e fora do CAPS, culminando com a apresentação da peça de Teatro Fórum "A Novidade Aparecida".

\section{Afetos e novidades aparecidas no Teatro do Oprimido na saúde mental}

Os resultados apontaram para 3 categorias de análise que se relacionam a como os usuários foram afetados e afetaram os colegas nas oficinas de Teatro do Oprimido, são elas: singularidade e subjetividade, o sofrimento psíquico e a potência de agir e os efeitos que a peça produz. O grupo se mostrou mobilizado desde o início, através de sua expectativa e desejo de "atuar", como disse um dos participantes (W., Diário de Campo, 27/01/2017, p.6) no segundo dia.

\section{Singularidade e subjetividade}

Por meio do embasamento teórico deste trabalho, sabemos que o encontro entre os corpos e as mentes podem gerar afecções e afetos positivos ou negativos, ativos ou passivos e que, a partir destes, podemos agir com liberdade ou estar submetidos à servidão. Podemos funcionar apenas na imaginação, isto é, criar imagens sobre as coisas (causa inadequada), mas também podemos ser a causa adequada das nossas ações na medida que conhecemos melhor o que se passa conosco.

Aprendemos com Espinosa (2016) que estamos sempre atuando nos polos da passividade, sofremos, mas também somos ativos, perseveramos na nossa existência, isto é, desejamos. Neste sentido, a produção de subjetividade pode atuar nestes dois polos, no entanto o que Espinosa nos ensina com sua filosofia é que, só através da alegria, podemos nos tornar livres. Tanto na alegria quanto na tristeza podemos sentir flutuações imaginárias da nossa potência de agir. Podemos adotar uma postura alienada em relação à vida ou apostar na criação. 
O sofrimento psíquico e a ideia de incapacidade, impossibilidade, doença, estão sempre permeando a vida das pessoas que fazem tratamento na saúde mental, elas trazem a marca, o estigma, a discriminação vivida em vários contextos sociais: na família, na escola, no trabalho, na rua, para falarmos apenas de alguns.

Neste sentido, mesmo que não se reflita, que não tenhamos consciência das relações entre oprimido e opressor, elas estão aí. São relações em que necessidades fundamentais são negligenciadas e através do rótulo as pessoas são marcadas em lugares de inferiorização.

O processo de relatar as histórias não foi um processo nem difícil nem fácil, mas sim um momento que fez emergir a força e o sofrimento implícito nas histórias, houve muito acolhimento e o grupo teve a oportunidade de se sentir à vontade e confiante da importância desta partilha, e que vinha sendo e foi um território propício para isto, um território propício para o surgimento de novos modos de subjetivação e produção de subjetividade.

Foi um processo muito rico, de acolhimento, de escuta, de valorização da dor do outro, mas também de identificação e de percepção da carga que cada história trazia para pensarmos aspectos particulares, singulares e coletivos inerentes à loucura, ao sofrimento. Talvez, nesse momento, o grupo possa ter clarificado mais o sentido do oprimido do Teatro do Oprimido. Como pontua Et. (DIÁRIO DE CAMPO, 20/01/2017, p. 5), muitas vezes não percebemos que a opressão também está dentro de nós mesmos, ou que temos possibilidades de enfrentar a opressão.

Sair da mente e ir para o coração, porque a mente é opressora, a mente é oprimida. Se você deixar a mente de lado, se você não vai na onda da mente, se você não se identifica com as coisas da mente. Precisa de meditação. Meditar é sair da mente e ir para o coração. [...]. Podemos ir além do coração. [..] Coração é teatro, é música, [...]. Fazer a pergunta quem sou eu? Pergunta para tirar o opressor e o oprimido de dentro de você. (ET., Diário de Campo, 20/01/2017, p. 5).

Essa capacidade de deixar fluir proposta por Et. não é uma tarefa fácil de exercitar em nossa sociedade. Estamos acostumados a funcionar presos às imagens que fazemos de encontros que tivemos e nos geraram desconforto, tristeza, constrangimento, e também somos moldados por padrões culturais e sociais que nos são passados desde criança. Assim, temos medo, ódio, desesperança e outros sentimentos que podem nos levar ao desvalor e às impossibilidades.

Nos ensaios da peça e nos vários espaços de produção da estética do oprimido, os participantes foram afetados: desenhando, poetizando, coreografando, explorando ritmos, ensaiando a construção de músicas e criando sonoplastia para a peça. As expressões plásticas transmitiram sentimentos, apropriações da história, compartilhamento de vivências, afetos, percursos vividos, expressando quem sabe um envolvimento, uma identificação com aspectos da história da protagonista. Fizemos durante o processo: acrósticos, poesias, tentativa de criação de uma música, entre outros. A arte e seu poder de afetação singular, sensível. 
A construção do cenário por R. foi um momento ímpar, surpreendeu a todos a sensibilidade de expressar no tecido o interior dos dois principais cenários onde se desenvolvem as cenas da história, a casa de Maria Aparecida e o hospital onde ela é internada e permanece durante sua gravidez. Surpreendeu pela característica do usuário de permanecer muito calado e quieto. Cenário muito rico de detalhes visuais, simbólicos, uma produção estética oferecendo à peça uma maior possibilidade de expressar para a plateia os elementos sentimentais, físicos e ambientais da história: da casa, um grande sofá, a televisão, quadro com flores na parede; e do hospital, a balança de pesar, a cruz, o relógio e a caveira simbolizando, quem sabe, a duração do sofrimento, e até uma placa de proibido fumar (Figura 1).

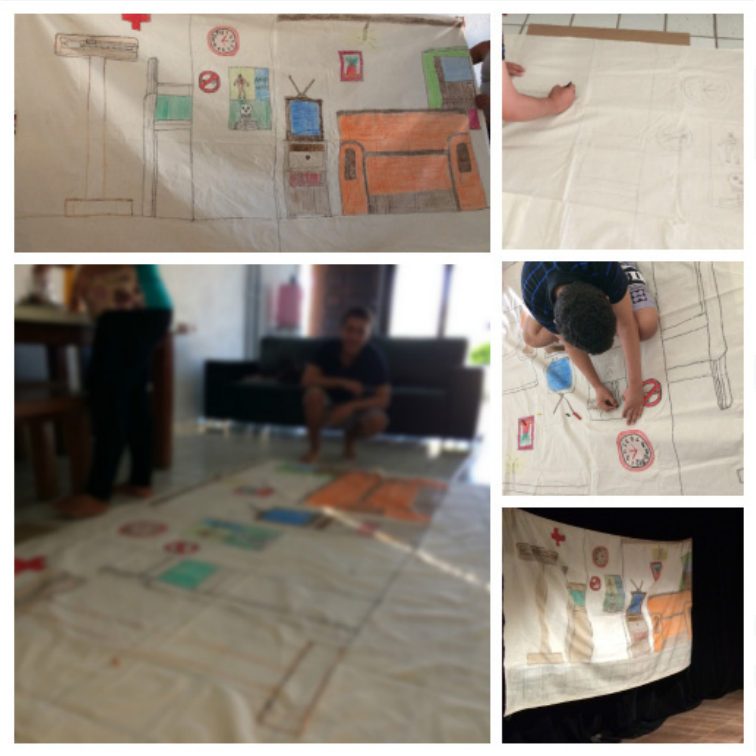

Fonte: $A$ autora (2018).

A arte - a estética - proporcionou a todos um conhecimento melhor e uma maior interação com R., ver seus desenhos, sua energia e movimento que não conhecíamos no dia a dia. Foi incrível esta produção de R., talvez tenha sido o ápice de seu envolvimento com o teatro e de seu relacionamento e compartilhamento de produção e troca com os colegas e colaboradores no CAPS durante todo o seu tratamento.

\section{O sofrimento psíquico e a potência de agir}

O Teatro do Oprimido possibilitou o encontro com a arte, a estética, com as possibilidades de sentir o corpo, de experimentar o novo e passar a se perceber e perceber o outro de formas diversas, expandindo assim novos afetos e novas formas de agir. Para nós terapeutas, e principalmente nós terapeutas ocupacionais, a teoria dos afetos de Espinosa traz um importante embasamento, o entendimento da dinâmica afetiva e sua relação com as possibilidades de produção de vida, isto é, a capacidade de agir, de sair da passividade. 
"A Novidade Aparecida" trouxe o sofrimento transvertido em crítica, possibilidade de sentir e comunicar de outra forma. Delirar em ato, talvez, como uma tentativa de dar voz a estas realidades, debatê-las e ensaiar para transformar esta realidade no e com o Teatro do Oprimido. Penso que os participantes fizeram isso, e continuam ainda hoje com este desejo. 0 Teatro do Oprimido parece se revestir para eles neste esforço, apetite, desejo de perseverar na existência, como nos aponta Espinosa (2016). Em muitos momentos, quando não temos clareza do que podemos ou sentimos, esse esforço é deixado de lado, esmorecemos, desanimamos, é normal, faz parte. A consolidação da experiência que se manifesta e é alcançada pelas intensidades vividas é que proporciona que este esforço se torne consciente e se consolide um desejo. Desejo e existência como busca de alegria, de afeto, de ser reconhecido, de sair dos impasses do sofrimento.

Para além de certezas ou continuidades espaço-temporais, vínculos particulares foram construídos e singularizados, como é o caso de alguns vínculos entre os participantes, e um vínculo particular se deu com o Teatro, com o Teatro do Oprimido.

Ouvir as histórias de opressão foi impactante. A força de trazer para a cena uma história de opressão vivenciada pôde produzir algo, transformar, fazer reexistir ou clarificar a opressão vivida para o protagonista e para os outros. Trazer para cena desvela muitos elementos que as palavras não conseguem transmitir, permitindo ao final debater todos os elementos encenados, muitos que não foram revelados através do contar a história. Aqui podemos demonstrar também o caráter político do Teatro do Oprimido e da Filosofia prática de Espinosa que, através da Razão, do entendimento do que se passou na história de opressão vivida, podemos aprender a transformá-la e percebemos toda a dor e sofrimento e o desejo de buscar as alternativas (DELEUZE, 2002; SPINOZA, 2016).

Os jogos demonstraram um potencial muito grande de mobilização dos participantes. Segundo El. (Diário de Campo, 03/02/2017, p. 9) "é a preparação para o teatro". Temos muito a dizer sobre isso, muitas contribuições, surpresas ou não, o mais importante é que a cada semana saíamos mais ricos, mais tocados, mais afetados. A análise do diário de campo faz emergir com mais detalhes a crescente mobilização que aconteceu em cada encontro em relação à realização dos jogos, o clima de alegria e troca de aprendizados, de afetos, de energia.

Nas palavras de Boal (2015), passo a relatar a importância do preparo do corpo através dos exercícios que para ele servem para o conhecimento do corpo nas suas possibilidades e limites, uma "reflexão física". Já os jogos são um diálogo, a "expressividade dos corpos como emissores e receptores de mensagens [...] eles exigem um interlocutor, eles são 'extroversão'" (IDEM, p.73).

Mas como podemos esperar que as emoções se manifestem "livremente" através do corpo do ator, se tal instrumento (nosso corpo) está mecanizado, muscularmente automatizado e insensível em $90 \%$ de suas possibilidades? Uma nova emoção, quando a sentimos, corre o risco de ser cristalizada pelo nosso comportamento mecanizado, pelas nossas formas habituais de agir e de nos expressar. [..] o ator como todo ser humano, tem suas sensações, suas ações, 
suas reações mecanizadas, e por isso é necessário começar pela sua "desmecanização", pelo seu amaciamento, para torná-lo capaz de assumir as mecanizações da personagem que vai interpretar. As mecanizações da personagem são diferentes das mecanizações do ator. É necessário que o ator volte a sentir certas emoções e sensações das quais já se desabituou, que amplifique a sua capacidade de sentir e de se expressar. (BOAL, 2015, p. 73).

A mecanização a que estamos submetidos diariamente nos leva a funcionar a partir de imagens e preconceitos impostos pela mídia, pela cultura, pela forma como fomos educados, pela religião. Espinosa (2016) aponta para a importância do corpo, nossa mente habita nosso corpo e é formada a partir do que vivenciamos, é a ideia do nosso corpo; quanto mais modificações meu corpo pode experimentar, mais potência eu serei capaz de produzir. Mente e corpo agem e sofrem juntos, de forma concomitante. A desmecanização implica nesta possibilidade de eu conseguir perceber meus próprios desejos, de abandonar ideias preconcebidas ou preconceitos impostos e buscar minha necessidade de satisfação. Espinosa (2016) aponta a necessidade de se liberar dos afetos-paixões que são nocivos à nossa vida.

Os dois primeiros meses de oficinas foram fundamentais para o grupo se abrir para novas vivências, discutir e descobrir novas maneiras de enfrentamento dos sentimentos cotidianos, procurar linhas de fuga para os impasses do cotidiano.

As vivências e os afetos aos poucos se intensificaram através dos jogos. E, neste sentido, já no primeiro encontro, a partir do que o Ud. ia sinalizando que os jogos poderiam estimular em nós, reflexões e expectativas foram trazidas, uma delas foi "trabalhar o medo de participar" (ELL., Diário de Campo, 20/01/2017, p. 3). Assim a dúvida gera as superstições, os preconceitos, o medo, e outros sentimentos e instabilidades. "O medo, por outro lado, é uma tristeza instável, surgida igualmente da imagem de uma coisa duvidosa". Podemos aqui perceber o desejo de participar, mas também a dúvida, a incerteza talvez do que posso sentir, do que posso ou não ser capaz. Em relação ao oprimido, questionamentos foram importantes nesse processo, perguntava-se quem são os oprimidos, os opressores? Respostas também surgiam, como, por exemplo, opressores são "as pessoas que não amam, que não sabem amar" (ET., Diário de Campo, 20/01/2017, p. 4) e perguntas como "esse oprimido é para tirar a timidez? (M.C., Diário de Campo, 31/03/2017, p.30). Há em nossa sociedade muita exclusão, mas por que isto acontece? O Teatro do Oprimido tem essa pergunta. O que podemos fazer? Falamos da capacidade de a criança brincar, dramatizar a partir dos objetos, transformando-os no enredo da sua história, dando asas à imaginação, no entanto, a sociedade e a escola formal nos impõem um padrão, nos forçando a atuar, perceber e agir com foco neste padrão de realidade das coisas. O Teatro do Oprimido quer possibilitar uma expressão mais livre, ao alcance de cada um, sem limitar as imagens que criamos sobre as coisas e sobre o que vivenciamos, é preciso sentir para depois conhecer. Neste sentido, não quer restringir a um padrão de funcionamento da sociedade, padrões de comportamento, rígidos, estabelecidos pelas instituições, tais como religião, escola, família, estado, isto é, relações de poder. Uma pessoa do grupo disse que somos nós os oprimidos, mas em seguida disse não saber o que é esta palavra. Outra pessoa 
disse que ser oprimido, "cada um tem um caso diferente, depende das circunstâncias, do momento, e o tempo" (EL., Diário de Campo, 20/10/2017, p.4).

"Mas o opressor também é oprimido porque que ele ignora que pode ser diferente" (ET., Diário de Campo, 20/01/2017, p. 4). Ou ele não quer? Na sociedade vivenciamos vários conflitos e situações de opressão, violência, necessidades que nos sãos negadas, situações em que nos discriminam.

M.C. (Diário de Campo, 20/01/2017, p.5) aponta a necessidade de vencer a discriminação, nos fortalecer, quem sabe, para poder enfrentar quando "discriminam a gente para trabalho e para atividades na sociedade". A discriminação é uma opressão muito vivenciada e relatada pelos participantes. Também foi rico o diálogo sobre como enfrentar o opressor, além do sentimento de opressão incorporado e não superado por nós. Como passar uma vassoura e tirar da humanidade, da vida das pessoas, o opressor e o oprimido?

As oficinas proporcionaram bons encontros e/ou jogos que possibilitaram o diálogo e o debate de como reagir a estes afetos. Os jogos e as atividades de estética foram realizados durante todo o percurso, no entanto, durante os oito primeiros encontros (de 20/01/2017 à 24/03/2017), quando iniciamos o processo de relatar as histórias e construir a peça, fizemos um mergulho na experimentação. O objetivo era acordar o corpo, "desmecanizar" (BOAL, $2005,2009,2015)$ os sentidos e o corpo para o exercício do teatro, trabalhar a criatividade, experienciar novas formas de andar, de ver, de se relacionar com o outro, de escutar, de perceber, de se movimentar, trabalhar intencionalidades, se abrir para deixar vir o novo, inventar novas palavras, gestos, imagens, atualizar, como nos propõe a cartografia, deixar emergir o que já está aí. Afetar e ser afetado pelo outro de novas formas, potencializar os afetos.

Um dos jogos que mais exercitamos desde o começo foi o Jana Cabana e um dos que os participantes mais se identificaram e solicitam até hoje. O desafio do jogo é, atendendo ao comando de jana, cabana ou tempestade, conquistar seu lugar, e não mais ficar fora do jogo. Este jogo e o jogo do gato e rato foram relatados como os mais difíceis, pois demandavam agilidade, mobilização de energia intensa, planejamento motor, criação de estratégias e integração dos sentidos.

U - Esse jogo trabalha com a visão, estar nesse vuco vuco ${ }^{1}$, você conseguir ver o espaço que você pode ir naquela confusão, trabalha a questão da visão.

M.C. - A gente para e pensa o que vai fazer. Se eu vou pra ali, se vou para aqui.

Cl. - Por que às vezes a gente se desorienta e outras não? É uma coisa pra gente pensar. Às vezes a gente sabe, mas a gente não faz porque acha que o outro sabe mais.

Udson - fica tenso. Será que às vezes acontece isso. A gente vem muito de uma escola que diz que tem que ser assim, a gente só pode, só se a gente souber fazer e se a gente souber que acertar.

Et. - Se usa esse verbo, tem que isso, tem que aquilo. Você tem que relaxar, repare o título do livro? 
El. - Sim, é a preparação para o Teatro.

Ell. - Tem que fazer aos poucos, impor não, se impor aí, já fica difícil. (DIÁRIO DE CAMPO, 03/02 /2017, p. 8).

Neste sentido, em relação ao Jogo Jana Cabana, o tema discutido foi a desorientação, fica uma bagunça disseram. Como nos sentimos na bagunça? O que sentiram no jogo Jana Cabana? Descreveram se sentir atordoados, desorientados no primeiro momento, "depois me senti uma criança" (EL., Diário de Campo, 03/02/2017, p.10). Este jogo foi descrito como divertido, inclusive nos momentos de "ficar à toa" (ET., Diário de Campo, 03/02/2017, p.8), bom por fazer as pessoas interagirem, foram discutidas também várias opiniões sobre quem fica de fora, fica excluído, fica com o poder para dizer a palavra que quiser e daí reconquistar um lugar.

M. C. - Eu vejo a tempestade assim como a nossa vida, às vezes a gente está com a vida turbulenta, não tem tempo para nada. Corre, corre pra lá, corre, corre pra cá. Às vezes não para pra falar com os amigos.

Ell. - A vida da gente às vezes é uma tempestade, uma hora tá bem, outra hora está atribulado e esse dinâmica é muito boa pra pensar. Você vê tudo bagunçado e depois vai se ajeitando.

E. - É brincadeira de louco mesmo, sai de dentro, depois vai para fora de novo. Fiz tudo errado, entrei no canto errado, aí entrava no canto certo, ficava sozinho.

Ell. - O pior é ficar sozinho. (DIÁRIO DE CAMPO, 03/02/2017, p. 7).

Outro aspecto interessante que foi trazido no diálogo foi o político, as forças que nos levam a agir desta ou daquela forma, a forma como fomos moldados na sociedade que vivemos.

Et. - A sociedade que a gente vive é a sociedade da eficiência. Se você não é eficiente, você não é útil, você não sabe fazer alguma coisa, você não tem valor, se você tira 5, 2 ou 1 você fica triste, se você tira dez, fica alegre. Você está sofrendo dessa influência, que fica incutida nas pessoas de que elas têm que ser inteligentes. [...]

$\mathrm{Cl}$. - Mas aqui é o momento de vocês sentirem, esses jogos querem o quê? Tirar essas ideias que estão encravadas na minha cabeça. Eu posso, não posso, quero, não quero, sou isso eu sou aquilo. Na hora do jogo tem que deixar vir. Sintam, olhem o colega, como o colega está. Como a El. Falou, esses jogos botam a gente ativo, botam a gente atento. (DIÁRIO DE CAMPO, 24/02/2018, p. 23).

Podemos, assim, pontuar como os jogos foram introduzindo novas experimentações, novas formas de encontro, a ativação e a criação de imagens e ideias mais adequadas do que se passou com cada um de nós, os diálogos ao final de cada oficina ensaiavam a nossa possibilidade de conhecer mais sobre nós mesmos e sobre o outro, a assim abrir mais possibilidades de refrear nossos afetos-paixões e construir os afetos-ações.

Nestes jogos, pudemos constatar que nosso corpo pode muito mais do que tínhamos conhecimento, e neste sentido produzimos ótimos encontros, muita alegria e, como nos disse 
El., tivemos uma ótima "preparação para o teatro" (DIÁRIO DE CAMPO, 02/03/2017, p.15). Nosso corpo se sensibilizou, se potencializou para o teatro.

O momento de relatar as histórias, o qual se deu entre 20 março a 26 de abril de 2017, surpreendeu e emocionou a todos nós, por vários motivos, pelo cuidado com que cada um acolheu a história do colega, pela força emotiva da história de cada um. O processo de relato e escolha das histórias aconteceu de forma gradual. Inicialmente, Ud. pediu que os participantes se reunissem em duplas e cada um deveria contar para o colega uma história de opressão vivida, alguma necessidade que não tivesse sido satisfeita em algum momento da vida por impedimento de alguém, algum incômodo ou constrangimento gerado. Depois, as duplas se juntaram a outras duplas formando dois grandes grupos que compartilharam suas histórias e escolheram duas das histórias que o grupo quisesse atuar, transformar em uma peça. Todas as histórias eram fortes e traziam temáticas importantes para o grupo: abandono, gravidez na adolescência, manicomialidade, agressão por palavras ou ofensas, entre outros. Cada grupo trouxe para o grupão duas histórias entre as relatadas no grupo, totalizando 4 histórias, sendo depois escolhidas 2 histórias para serem trabalhadas teatralmente.

No CAPS, é comum o relatar histórias, no entanto este momento marcou algo diferente, contar histórias para encená-las, contar histórias que tiveram desejos não satisfeitos. Essa clarificação do oprimido e do opressor, diálogo pela busca de transformação, levar estas problemáticas para dialogar com as pessoas e ganhar reconhecimento, ser aceito, ser visto, ser famoso.

Nas apresentações de "A Novidade Aparecida", espontaneamente, aconteciam pequenos desvios do texto original, isto é, do seguimento da história de M.A. que, no entanto, não os paralisavam, mas diferentemente de um ator profissional, que improvisa uma outra fala.

Durante os ensaios, quando ocorriam fatos similares, H. de S., estudante de teatro e um dos bolsistas do projeto de extensão, sempre sinalizava a beleza desta interpretação e pontuava como eles estudantes de teatro ou os atores não conseguem atuar desta forma, espontânea, sair do texto espontaneamente, transformando estes desvios em elemento de encenação, em elemento teatral.

M. A., na cena que é amarrada, parece buscar uma (re)existência, encarna uma oprimida engraçada, um dos pontos altos da opressão vivida. No palco, como ela mesma, M. A. diz "a gente tira a pessoa e entra a personagem" (DIÁRIO DE CAMPO, 26/04/2017, p. 47), na personagem, que é ela mesma reexistida, pode rir e fazer rir do sofrimento como revivê-lo de outra maneira e apresentá-lo ao público e seus familiares revestido de graça e questionamento.

\section{Que efeitos a peça produz}

O Teatro do Oprimido extrapola esse caráter de representação, trouxe o real e o irreal transformado em possibilidade, em invenção. 
"A Novidade Aparecida" trouxe o sofrimento transvertido em crítica, possibilidade de sentir e comunicar de outra forma. Delirar em ato, talvez, como uma tentativa de dar voz a estas realidades, debatê-las e ensaiar para transformar esta realidade no e com o Teatro do Oprimido. Penso que os participantes fizeram isso. O Teatro do Oprimido parece se revestir para eles neste esforço, apetite, desejo de perseverar na existência, como nos aponta Espinosa (2016). Em muitos momentos, quando não temos clareza do que podemos ou sentimos, esse esforço é deixado de lado, esmorecemos, desanimamos, é normal, faz parte. A consolidação da experiência que se manifesta e é alcançada pelas intensidades vividas é que proporciona que este esforço se torne consciente e se consolide um desejo. Desejo e existência como busca de alegria, de afeto, de ser reconhecido, de sair dos impasses da doença, reafirmando, então, o sofrimento, a sua superação e o desejo de mais vida. Falar do sofrimento, das opressões, revivê-las no teatro pode ser desanimador também. Então, transvestir a dor, o sofrimento, as opressões em riso, extrair esse elemento foi uma das potências que os participantes descobriram, inventaram. $\mathrm{O}$ riso, as formas engraçadas de trazer a dor, o deslocamento de papéis/personagens, espontaneidade em atuar em cena algo conhecido na realidade, foram sendo descobertos a cada ensaio, talvez o sofrimento tenha sido diluído durante o processo e na estreia da peça pôde culminar em riso e novas formas de ver, sentir, ouvir e compartilhar o sofrimento.

No primeiro dia de construção e apresentação das cenas, ao final, o comentário era sobre a diferença significativa entre ouvir a história e interpretar a história, dar vida à história, "Cai na real da história, tirar a pessoa e entrar na personagem" (M. A., DIÁRIO DE CAMPO, 26/04/2017, p. 38). Vendo os vídeos da construção das cenas com a participação dos atores e a posterior apresentação para o grupão, percebia-se que era sempre seguida de muito interesse; a construção era orientada por Maria Aparecida, que relatava os detalhes da história, dos personagens de sua história, seu jeito de agir, suas falas. A cada semana eram trazidos mais elementos, cada um ia se apropriando da história, do espaço, da maneira como deveria se posicionar em relação à plateia. Uma fala muito significativa esteve presente desde o início no discurso de M. A., "eu vou criar meu filho sozinha" (DIÁRIO DE CAMPO, 23/06/2017, p. 51).

Chegamos aqui a um ponto importante na filosofia de Boal: oprimido não é um deprimido. Um oprimido deseja algo, algo de que é impedido de realizar pelas forças do poder e da opressão, mas o oprimido procura soluções, luta pela mudança. (BARBOSA, 2011, p.40).

M. A. trazia essa fala como um refrão, como esse desejo que tinha de lutar, de vencer, de criar seu filho, ainda que sozinha, mas muito bem, dando o seu melhor, como tanto ela durante seu relato da história, quanto a sobrinha e o próprio filho puderam dar como depoimento ao final da peça. Esse desejo foi expresso em falas da M. A. e nos depoimentos do filho e da sobrinha, que reafirmaram seu desejo, hoje concretizado.

O processo foi sendo construído com a orientação do nosso coringa ${ }^{2}$ de Teatro do Oprimido, mas na verdade o processo foi completamente conduzido e dirigido pela protagonista da história, que ia contando sua história e orientando a construção das cenas, das falas, das interpretações com muita habilidade, "faz assim"... ela dizia, ao mesmo tempo que corrigia, 
sem invalidar a construção do colega, e deixando a eles ou a elas a possibilidade de criar. Sua expressividade, sua segurança, seu desejo de contar, de reexistir na sua história iam crescendo a cada dia e surpreenderam bastante. M. A. participou da primeira experiência de Teatro do Oprimido em 2015 e encenou a mãe da protagonista na peça "Marcas da Opressão", ela mesma diz que se sentiu diferente.

A construção artística é mais uma consolidação em processo que modifica lugares, territórios de adoecimento, papéis sociais cristalizados na família, no próprio CAPS, nas relações entre as pessoas, ela extrapola para o campo sociocultural e político. A apropriação do campo sociocultural também se deu assumindo o papel de atores/atrizes, facilitadores e multiplicadores de Teatro do Oprimido em formação. A cada apresentação eles exercitaram o manejo de jogos, a codireção da peça, a curingagem e a comunicação com o público na condução do fórum. Protagonismo, empoderamento, desinibição, segurança e ampliação da capacidade de comunicar sentimentos são os efeitos vivenciados, levando arte e conteúdos reais da vida para discutir com estudantes, simpatizantes, familiares e profissionais da saúde mental.

Problemas vivenciados por muitas pessoas na atualidade, problemas que podem dar origem a patologias, aprendizado singular e potente para um público, no caso do público da saúde mental, acostumado com a doença.

Foi um processo muito bonito mesmo, em muitos momentos foi difícil a construção desta narratividade, muito ficou no fluxo vivido, difícil trazer em palavras, mas também muito prazeroso recordar, revivenciar, conseguir traduzir. Conseguir escrever com poesia toda esta emoção vivida foi um processo mais que especial.

\section{Considerações finais}

O Teatro do Oprimido trouxe a possibilidade de dialogar corporalmente, expressivamente e esteticamente com as marcas da opressão, mas também com os desejos, com os afetospaixões de alegria e tristeza e nossas possibilidades e impossibilidades de singularização. Construção coletiva, diálogo e entendimento, afecção e afetação, encontros dentro e fora do CAPS, que possibilitaram o enfrentamento do sofrimento.

Novidades exercitadas em um "(des)praticar" a noção de clínica (VASCONCELOS, 2018) para potencializar a vida na clínica, no serviço e fora dele. Praticar o teatro como novidade na clínica e também o caráter pedagógico do Teatro do Oprimido, nos ajudando a: dialogar, pensar, transformar e fazer existir outras formas de ser e agir. Ser ator, ser atriz, ser participante e protagonista, não mais usuário ou doente, e sim ser coprodutor do conhecimento.

Essa visão produtiva da subjetividade, cujos encontros são produtores de afecções e afetos capazes de transformar nossa potência de existir, foi produzida nos nossos encontros: participantes, multiplicador de Teatro do Oprimido, bolsistas, trabalhadores do CAPS, plateia, estudantes. Foram muitos encontros, encontros com vários formatos, afecções, afetos, intensidades, fluxos, reverberações, repetições e suas diversificações. Passamos da imaginação 
ao conhecimento daquilo que pulsa em nós, do sofrimento que não mais só nos perturba, mas em conhecendo melhor, podemos falar dele de outra forma, como a desafiá-lo ou transfigurar sua natureza. Descobrir a partir do sofrimento outras possibilidades de sentir, de agir com ele, e sair dele, de expulsá-lo, enfim... alternativas. Nos transformaram, ou iniciaram processos de construção de outras formas de ver, de perceber, conhecer e de agir sobre a nossa realidade. Estamos em processo... em um belo, intenso e afetuoso... processo.

\section{Referências}

BARBOSA, Inês Beatriz. Jovens e teatro do oprimido: (re) criando a cidadania, (re) construindo o futuro. Dissertação (Mestrado em Associativismo e Animação Sócio Cultural). Instituto de Educação. Universidade do Minho. 2011.

BOAL, Augusto. Teatro do Oprimido e outras poéticas políticas. 7. ed. Rio de Janeiro: Civilização Brasileira, 2005.

BOAL, Augusto. Jogos para atores e não atores. São Paulo: Cosac Naify, 2015, 416 p.

BOAL, Augusto. A Estética do Oprimido. Rio de Janeiro: Garamond, 2009.

BOAL, Augusto. A Árvore do Teatro do Oprimido. In: Metaxis: informativo do Centro de Teatro do Oprimido, CTO-Rio. n.4 2008. Tema: Teatro do Oprimido de Ponto a Ponto. Rio de Janeiro: Master Print, 2006. Disponível em: http://ctorio.org.br/novosite/wp-content/uploads/2009/09/ METAXIS.pdf. Acesso em: 14 out. 2013.

CANGUILHEM, George. O normal e o patológico; tradução de Mana Thereza Redig de Carvalho Barrocas; revisão técnica Manoel Barros da Motta; tradução do posfácio de Piare Macherey e da apresentação de Louis Althusser, Luiz Otávio Ferreira Barreto Leite. 6. ed. rev. Rio de Janeiro: Forense Universitária, 2009.

CHAUÍ, Marilena A nervura do real: imanência e liberdade em Espinosa, volume II: Liberdade / Marilena Chauí. 1. ed. São Paulo: Companhia das Letras, 2016. Não paginado.

DELEUZE, Gilles. Espinosa: filosofia prática. São Paulo: Escuta, 2002. 144 p.

DELEUZE, Gilles; GUATTARI, Felix. Mil Platôs: capitalismo e esquizofrenia 2. Tradução de Suely Rolnik. 2. ed. São Paulo: Editora 34, v. 4, 2012, 200 p.

FERREIRA, Amauri. Introdução à filosofia de Spinoza / Amauri Ferreira. 1. ed. São Paulo: Editora Quebra-Nozes, 2009.

SANTOS, Bárbara. Teatro do Oprimido: Raízes e Asas uma teoria da práxis. 1. ed. Rio de Janeiro: Ibis Libris, 2016, 532 p.

SPINOZA, Benedidus de, 1632-1677. Ética / Spinoza; [tradução de Tomaz Tadeu]. - Belo Horizonte: Autêntica Editora, 2016. Título original: Ethica. ISBN: 978,85-7526-381-5

VASCONCELOS, Michele de Freitas Faria de. Parecer de Defesa de Mestrado em Educação. Programa de Pós Graduação em Educação, Universidade Federal de Alagoas. Aracaju - SE, ago. 2018. 4 p. 


\section{Endnotes}

1 Vuco vuco - nesta confusão, movimentação, agitação no bom sentido.

2 Coringa de Teatro do Oprimido - é o nome dado ao mestre de cerimônias do Teatro Fórum, ele dinamiza, aquece, interpela a plateia para realizar o Fórum debatendo, clarificando o contexto e os elementos presentes na história da protagonista. Para saber mais sobre como o Coringa interpela, estimula e facilita os expectadores a entrar em cena com alternativas para a opressão vivida, ver Boal $(2015$, p. 303).

Artigo recebido em: 29/03/2022

Aprovado em 02/11/2020 